\title{
Loss of RUNX3 is significantly associated with advanced tumor grade and stage in endometrial cancers
}

\author{
DONGJUN JEONG ${ }^{1}$, HYUNGJOO KIM ${ }^{1}$, AELI RYU ${ }^{2}$, JAEGUN SUNWOO ${ }^{2}$, \\ SEUNG DO $\mathrm{CHOI}^{2}$, GYE HYUN NAM ${ }^{3}$ and SEOB JEON ${ }^{2}$ \\ ${ }^{1}$ Soonchunhyang Medical Science Research Institute; ${ }^{2}$ Department of Obstetrics and Gynecology, \\ Soonchunhyang University Cheonan Hospital, Cheonan, South Chungcheong 31151; \\ ${ }^{3}$ Department of Obstetrics and Gynecology, Soonchunhyang University Bucheon Hospital, \\ Bucheon, Gyeonggi 14584, Republic of Korea \\ Received May 6, 2016; Accepted May 5, 2017
}

DOI: $10.3892 / \mathrm{mmr} .2018 .8915$

\begin{abstract}
Loss of runt-related transcription factor 3 (RUNX3) has been reported in various cancers, and one of the mechanisms mediating loss of RUNX3 expression is DNA methylation. However, the role of RUNX3 expression and its DNA methylation status as prognostic factors in endometrial cancer remain unclear. In the present study, the expression and promoter methylation of RUNX3 was examined in endometrial cancer tissues and cell lines, as well as their association with endometrial cancer prognosis. Fifty-five endometrial cancer tissues and two endometrial cancer cell lines (HEC1- $\alpha$ and Ishikawa) were studied. RUNX3 expression and promoter methylation were examined using reverse transcription-polymerasechain reaction(RT-PCR), methylation specific PCR (MS-PCR), and immunohistochemical staining. The demethylating agent 5-aza-2'-deoxycytidine (ADC) was used to reverse the methylation of the RUNX3 promoter. Loss of RUNX3 expression was observed in 50.9\% (27/53) of endometrial cancer tissues and in the HEC1- $\alpha$ cell line by immunohistochemistry and RT-PCR, respectively. Methylation of the RUNX3 promoter was observed in $62.2 \%$ (33/53) of endometrial cancer tissues, $12.5 \%$ (1/8) of normal endometrial tissues, and the HEC1- $\alpha$ cell line by MS-PCR. Tumor grade and stage were significantly correlated with loss of RUNX3 expression. The expression of RUNX3 was restored by treatment with ADC and resulted in growth inhibition in HEC1- $\alpha$ cells. The present results suggested that methylation may serve a critical role in the silencing of RUNX3 and loss
\end{abstract}

Correspondence to: Dr Seob Jeon, Department of Obstetrics and Gynecology, Soonchunhyang University Cheonan Hospital, 23-20 Bongmyungdong Dongnamgu, Cheonan, South Chungcheong 31151, Republic of Korea

E-mail: sjeon4595@gmail.com

Key words: endometrial cancer, runt-related transcription factor 3 , DNA methylation of RUNX3 expression may serve as a prognostic marker in endometrial cancer.

\section{Introduction}

Endometrial cancer is the most common female genital cancer in western countries, and the fourth most common cancer in women. Although the incidence of endometrial cancer is relatively low in Asian countries, it has increased by 6-7 fold in recent years (1). Several genetic abnormalities have been associated with endometrial cancer, including alterations in various tumor suppressor genes and oncogenes, such as phosphatase and tensin homolog, tumor protein p53, RAS and human epidermal growth factor receptor $2 /$ neu (2). Silencing of tumor suppressor genes by DNA methylation may play a critical role in the pathogenesis of various human cancers, including endometrial cancer. In addition, silencing by DNA methylation of various genes involved in cell cycle control, apoptosis, angiogenesis and mismatch repair may contribute to endometrial carcinogenesis (2).

Runt domain transcription factors, also known previously as polyomavirus enhancer binding protein 2 /core binding factors (PEBP2/CBFs), are targets of the transforming growth factor (TGF)- $\beta$ signaling pathway and important regulators of human development and tumorigenesis (3). The runt-related transcription factor (RUNX) family includes three isoforms: RUNX1, RUNX2, and RUNX3. RUNX1 and RUNX2 are associated with abnormalities in blood and bone formation, whereas loss of RUNX3 function has recently been reported to be associated with carcinogenesis in various cancers (4-10). Indeed, TGF- $\beta /$ RUNX3 signaling serves an important role in tumor suppression (3). The RUNX3 gene is located on chromosome 1p36, and deletion of RUNX3 from the short arm of chromosome 1 has been reported frequently in various types of tumors, including endometrial cancer, suggesting that one or more tumor suppressor genes exist on the short arm of chromosome 1 .

Loss of function of RUNX3 by promoter hypermethylation, protein mislocalization, and hemizygous deletion has been reported in several cancers, including gastric cancer, hepatocellular carcinoma, breast cancer, and lung cancer (5-8). RUNX3 
has been reported to function as a tumor suppressor in gastric cancer, and loss of RUNX3 expression has been reported in $\sim 45-60 \%$ of gastric cancer cell lines and gastric cancer tissues through hypermethylation of its promoter (5). Previous studies of the relationship between RUNX3 and endometrial cancer are limited, and results showing the frequency of methylation and loss of RUNX3 expression in endometrial carcinoma have not been consistent $(9,10)$. In addition, the relationship between hypermethylation of the RUNX3 promoter and loss of expression has not been determined, and the correlation between loss of expression and clinicopathological factors is unclear.

Therefore, the present study aimed to investigate RUNX3 protein expression and the methylation status of the RUNX3 promoter in endometrial cancer cell lines, normal endometrial tissues and endometrial cancer tissues, in order to determine the role of RUNX3 in endometrial carcinogenesis and its relationship with clinicopathological factors.

\section{Materials and methods}

Cell lines and culture. HEC-1 $\alpha$ cells were purchased from the American Type Culture Collection (Manassas, VA, USA), and Ishikawa cells were purchased from Sigma-Aldrich (Merck KGaA, Darmstadt, Germany). HEC- $1 \alpha$ cells were cultured in a $5 \% \mathrm{CO}_{2}$ incubator at $37^{\circ} \mathrm{C}$ using McCoy's 5a medium (Sigma-Aldrich, Merck KGaA, Darmstadt, Germany) and Ishikawa cells were cultured in a $5 \% \mathrm{CO}_{2}$ incubator at $37^{\circ} \mathrm{C}$ using Dulbecco's modified Eagle's medium (Gibco; Thermo Fisher Scientific, Inc., Waltham, MA, USA) supplemented with $10 \%$ fetal bovine serum.

Endometrial cancer tissues and normal endometrial tissues. A total of 53 endometrial carcinoma tissues and eight normal endometrial tissues were obtained during surgery or endometrial curettage at Soonchunhyang University Cheonan Hospital, (Cheonan, Korea) between January 1998 and December 2006. All endometrial cancers exhibited an endometrioid adenocarcinoma histology. Tumor stage was assessed according to the International Federation of Gynecology and Obstetrics staging system and differentiation grade was assessed according to the World Health Organization classification 1-3 system. The clinicopathological characteristics of the patients are described in Table I. Written informed consent was obtained from all patients, and the study was approved by the Institutional Review Board of Soonchunhyang University Cheonan Hospital.

Reverse transcription-polymerase chain reaction (RT-PCR). RT-PCR was performed in order to detect the expression of RUNX3 mRNA in the endometrial cancer cell lines, two normal endometrium and cancer tissues. Total RNA was extracted using a QIAamp RNA kit (Qiagen, Inc., Valencia, CA, USA). Reverse transcription was performed using $5 \mu \mathrm{g}$ total RNA with the Superscript II First-Strand Synthesis system (Thermo Fisher Scientific, Inc.) using oligo(dT) primers. The PCR components were as follows: $0.5 \mu \mathrm{l}$ forward primer (10 pmol), $0.5 \mu \mathrm{l}$ reverse primer (10 pmol), $1 \mu \mathrm{l}$ cDNA, $2 \mu 1$ $2.5 \mathrm{mM}$ dNTPs, $3 \mu \mathrm{l}$ of 5XQ buffer, $1 \mathrm{U}$ Taq DNA polymerase (Qiagen, Inc.) and $\mathrm{dH}_{2} \mathrm{O}$ to reach a final volume of $30 \mu \mathrm{l}$. The primer pair for the human RUNX3 forward, 5'-AGACAGCCT GGGCTGGTAAA-3' and reverse, 5'-TCAGATGAGTGCAGC
AGGTG-3'; and GAPDH forward, 5'-CTTAGCACCCCTGGC CAAG-3' and reverse, 5'-GATGTTCTGGAGAGCCCCG-3'. The PCR conditions were as follows: Initial denaturation for $15 \mathrm{~min}$ at $95^{\circ} \mathrm{C} ; 35$ cycles of denaturation at $95^{\circ} \mathrm{C}$ for $30 \mathrm{sec}$, annealing at $63^{\circ} \mathrm{C}$ for $30 \mathrm{sec}$ and extension at $72^{\circ} \mathrm{C}$ for $30 \mathrm{sec}$; and a final extension for $5 \mathrm{~min}$ at $72^{\circ} \mathrm{C}$. PCR was carried out using a thermal cycler (PTC-200; MJ Research, Inc., Waltham, MA, USA). PCR products were evaluated by electrophoresis on ethidium bromide-stained $2 \%$ agarose gels and by digital capillary electrophoresis.

Immunohistochemical staining. The Endometrial cancer tissue were embedded in paraffin following fixation in $10 \%$ neutral buffered formalin overnight at room temperature and sectioned at $4 \mu \mathrm{m}$. Immunohistochemical staining was performed to identify protein expression within the endometrial cancer tissues. To facilitate antigen retrieval, the sections were pretreated using heat-mediated antigen retrieval with sodium citrate buffer (0.01 M, pH 6.0) by boiling in a microwave for $20 \mathrm{~min}$, cooling at room temperature for at least $1 \mathrm{~h}$, and rinsing with distilled water three times for 3 min each. To block endogenous peroxidase, the sections were incubated in $3 \%$ hydrogen peroxide in methanol at room temperature for $20 \mathrm{~min}$. Next, sections were washed three times with distilled water, soaked in PBS $\mathrm{pH} 7.4$ for $3 \mathrm{~min}$, and then incubated with rabbit polyclonal antibody against human RUNX3 (39301; 1:100; Active Motif, Inc., Carlsbad, CA, USA) at room temperature for $1 \mathrm{~h}$. Sections were washed with PBS three times for 3 min each and then were incubated with secondary antibody EnVision HRP-Labelled Polymer anti-rabbit (K4002; Dako; Agilent Technologies, Inc., Santa Clara, CA, USA) for $30 \mathrm{~min}$ at room temperature. Thereafter, the sections were washed three times with PBS and reacted with the chromogen diaminobenzidine, followed by washing with distilled water. Sections were then counterstained with hematoxylin and mounted with DPX mounting medium. The slides were evaluated by a trained pathologist using an optical light microscope. Depending on the $\%$ of stained cells, quantification was performed according to the following classification: Staining intensity 0 , no stained cancer cells; +1 , positive in $<33 \%$ of cancer cells; +2 , positive in $33-66 \%$ of cancer cells; and +3 , positive in $>66 \%$ of cancer cells.

Genomic DNA extraction from tissues and cell lines. A G-spin Genomic DNA Extraction kit (Intron Biotechnology, Inc., Seongnam, Korea) was used for DNA extraction from cell lines and tumor tissues. To obtain DNA from paraffin blocks containing tumor tissues, microdissection was conducted as follows. First, 5-7 $\mu \mathrm{m}$ sections were cut from the paraffin blocks. Following deparaffinization, the blocks were hydrated through a graded series of alcohols to distilled water. Next, the sections were dried at room temperature. The tumor tissues were then scraped with a 24-gauge needle from dried tissue under a microscope at magnification, $\mathrm{x} 40$. The collected tissue was placed in $50 \mu \mathrm{l}$ of lysis buffer $(500 \mathrm{mM} \mathrm{KCl}, 150 \mathrm{mM}$ Tris- $\mathrm{HCl} \mathrm{pH} 8.0$, $15 \mathrm{mM} \mathrm{MgCl}$ and $1.5 \%$ Tween-20) containing proteinase $\mathrm{K}$ $(0.5 \mathrm{mg} / \mathrm{l})$. Samples were mixed well by vortexing and incubated for $24 \mathrm{~h}$ at $55^{\circ} \mathrm{C}$. Subsequently, DNA was extracted using the G-spin Genomic DNA Extraction kit and bisulfite modification, which converts unmethylated $\mathrm{CpG}$ cytosine to uracil, was carried out using an Epitech Bisulfite kit (Qiagen, Inc.). 
Table I. Expression of RUNX3 according to clinicopathological factors.

\begin{tabular}{|c|c|c|c|c|c|c|}
\hline \multirow[b]{2}{*}{ Clinicopathological factors } & \multirow[b]{2}{*}{ Number of cases } & \multicolumn{4}{|c|}{ RUNX3 expression score } & \multirow[b]{2}{*}{ Total } \\
\hline & & 0 & +1 & +2 & +3 & \\
\hline \multicolumn{7}{|l|}{ Age, years $(n=53)$} \\
\hline$<60$ & 28 & 12 & 13 & 3 & 0 & 16 \\
\hline$>60$ & 25 & 15 & 9 & 1 & 0 & 10 \\
\hline \multicolumn{7}{|l|}{ Tumor grade $(n=53)$} \\
\hline G1-2 & 39 & 16 & 20 & 3 & 0 & $23^{\mathrm{a}}$ \\
\hline G3 & 14 & 11 & 2 & 1 & 0 & 3 \\
\hline \multicolumn{7}{|l|}{ FIGO stage $(n=48)$} \\
\hline I & 35 & 11 & 20 & 4 & 0 & $24^{\mathrm{a}}$ \\
\hline III & 13 & 12 & 1 & 0 & 0 & 1 \\
\hline \multicolumn{7}{|l|}{ Myometrial invasion $(\mathrm{n}=48)$} \\
\hline$<50 \%$ & 21 & 6 & 12 & 3 & 0 & 15 \\
\hline$>50 \%$ & 27 & 17 & 9 & 1 & 0 & 10 \\
\hline \multicolumn{7}{|l|}{ Lymph node (n=48) } \\
\hline Yes & 4 & 0 & 0 & 0 & 0 & 0 \\
\hline No & 44 & 23 & 21 & 4 & 0 & 25 \\
\hline
\end{tabular}

${ }^{\mathrm{a}} \mathrm{P}<0.05$. RUNX3, runt-related transcription factor 3; FIGO, International Federation of Gynecology and Obstetrics.

Methylation specific PCR (MS-PCR). In order to determine the methylation status of the RUNX3 promoter, MS-PCR was performed. Primers specific for methylated DNA (M; forward, 5'-TATTCGTTAGGGTTCGTTCGT-3' and reverse, 5'-AAACAACCACGAAAAACGAC-3') and unmethylated DNA (U; forward, 5'-AAGTGGGAAAGT AGAAGTGGTG-3' and reverse, 5'-CCAAACAAACTA CAAACAACCA-3') were used. The PCR conditions were as follows: Initial denaturation for $15 \mathrm{~min}$ at $95^{\circ} \mathrm{C} ; 35$ cycles of denaturation at $95^{\circ} \mathrm{C}$ for $15 \mathrm{sec}$, annealing at $58^{\circ} \mathrm{C}$ for $50 \mathrm{sec}$ and extension at $72^{\circ} \mathrm{C}$ for $60 \mathrm{sec}$, and a final extension for $5 \mathrm{~min}$ at $72^{\circ} \mathrm{C}$. PCR was carried out in a thermal cycler (PTC-200; MJ Research, Inc.). PCR products were then subjected to capillary electrophoresis or electrophoresis on ethidium bromide-stained $2 \%$ agarose gels. The results were verified using a digital image analysis system. The positive control DNA template was a universally methylated DNA (S7821), and the negative control DNA template was a universally unmethylated DNA (S7822; both EMD Millipore, Billerica, MA, USA).

5-Aza-2'-deoxycytidine (ADC) treatment. Because methylation is a reversible modification, the DNA methyltransferase inhibitor ADC (Sigma-Aldrich; Merck KGaA) was used to examine whether gene expression was inhibited by promoter methylation. HEC1- $\alpha$ cells were treated with ADC at different concentrations $(0,0.5,1$ or $5 \mu \mathrm{M})$ for 3 days. Cells were then harvested for analysis of RUNX3 mRNA expression.

Cell survival. To evaluate the biological function of RUNX3, the viability of HECl $\alpha$ cells was analyzed following treatment with ADC using an MTT assay (Sigma-Aldrich; Merck KGaA), according to the manufacturer's instructions. Cell survival was calculated as the optical density value at $545 \mathrm{~nm} \times 100$.
Statistical analysis. All statistical analyses were carried out with SPSS version 13.0 software (SPSS, Inc., Chicago, IL, USA) using $\chi^{2}$, students-t test and one-way analysis of variance. $\mathrm{P}<0.05$ was considered to indicate a statistically significant difference.

\section{Results}

Patient characteristics. As described in Table I, the average age of the patients was $59.3 \pm 11.8$ years, and the histological grades were grade 1 or 2 in 39 patients $(73.6 \%)$ and grade 3 in 14 patients $(26.4 \%)$. A total of 48 patients underwent staging surgery, including hysterectomy, bilateral salpingo oophorectomy, pelvic lymphadenectomy, multiple peritoneal biopsy, and peritoneal washing cytology. According to the surgical pathology reports, clinicopathological factors were as follows: Stage I in 35 patients (72.9\%); stage III in 13 patients $(27.1 \%)$; myometrial invasion, less than half in 21 patients $(43.7 \%)$; and myometrial invasion, more than half in 27 patients (56.3\%).

RUNX3 mRNA expression and methylation of the promoter region of the RUNX3 gene in endometrial cancer cell lines. RUNX3 mRNA was expressed in Ishikawa cells but not in HEC1- $\alpha$ cells (Fig. 1A). In addition, results from MS-PCR revealed that the RUNX3 promoter region was methylated in HEC1- $\alpha$ cells but not in Ishikawa cells (Fig. 1B). RUNX3 mRNA expression was absent in two cases of fresh endometrial cancer tissue but was present in two cases of fresh normal endometrial tissues (Fig. 1A).

Loss of RUNX3 expression is correlated with clinicopathological factors. Immunohistochemical staining of tumor sections from 53 cases of endometrioid 
adenocarcinoma revealed that RUNX3 protein was expressed in 26 cases (49.1\%). Normal endometrial tissues surrounding the endometrial cancer exhibited strong RUNX3 protein expression (+3) and were selected as the positive control group (data not shown). RUNX3 protein expression was observed in the cytoplasm and was widely spread evenly throughout the samples (Fig. 2). Among 39 cases with grade 1 2 tumors, 16 cases $(41.0 \%)$ demonstrated negative staining, 20 cases (51.3\%) demonstrated +1 expression and only 3 cases $(7.7 \%)$ demonstrated +2 expression, among 14 cases with grade 3 tumors, 11 cases $(78.5 \%)$ demonstrated negative staining, 2 cases $(14.2 \%)$ demonstrated +1 expression and only 1 case (7.1\%) demonstrated +2 expression (Table I). Of the 53 patients, 48 underwent surgery, including total hysterectomy, bilateral salpingo oophorectomy, multiple peritoneal biopsy, pelvic lymphadenectomy, and peritoneal washing cytology. Therefore, more detailed staging information, as well as myometrial and lymph node invasion status, was available for these samples (Table I). Among 35 cases with stage I tumors, 11 cases (31.4\%) demonstrated negative staining, 20 cases $(57.1 \%)$ demonstrated +1 expression and 4 cases (11.4\%) demonstrated +2 expression, among 13 cases with stage III tumors, only 1 case (7.6\%) demonstrated +1 expression (Table I).

The RUNX3 expression pattern was compared to age, stage, grade, myometrial invasion and lymph node metastasis of the patients. The statistical analysis revealed that the higher histological grades were significantly associated with lower RUNX3 protein expression $(\mathrm{P}<0.05$; Table I) and that loss of RUNX3 protein expression was correlated with advanced stage $(\mathrm{P}<0.05$; Table I).

Methylation of the RUNX3 promoter is not correlated with clinicopathological factors. Methylation of the RUNX3 promoter region was observed in 33 of 53 cases $(62.3 \%)$ of endometrial cancer and in one of eight cases (12.5\%) of normal endometrial tissues (Fig. 3). Methylation was more frequently observed in tumor tissues than in normal tissues $(\mathrm{P}<0.05)$. However, there was no significant correlation between RUNX3 promoter methylation and clinicopathological prognostic factors (Table II).

Effects of ADC treatment on RUNX3 expression. RUNX3 mRNA expression was increased following $72 \mathrm{~h}$ of treatment with increasing concentrations of ADC in HEC1- $\alpha$ cells (Fig. 4), which were demonstrated in the present study to be negative for RUNX3 protein expression and positive for methylation of the RUNX3 promoter (Fig. 1). This result confirmed that silencing of RUNX3 in HECl- $\alpha$ cells occurred by methylation of the RUNX3 promoter region.

Effects of ADC treatment on cell growth. Cell viability was evaluated by MTT assay in HEC1- $\alpha$ cells following treatment with $\operatorname{ADC}(0,0.5,1,2.5$ and $5 \mu \mathrm{M})$ for $72 \mathrm{~h}$. The results demonstrated that ADC treatment inhibited cell growth in a concentration and time-dependent manner (Fig. 5).

\section{Discussion}

RUNX3, a target of TGF- $\beta$ and bone morphogenic protein signaling, serves an important role in development and

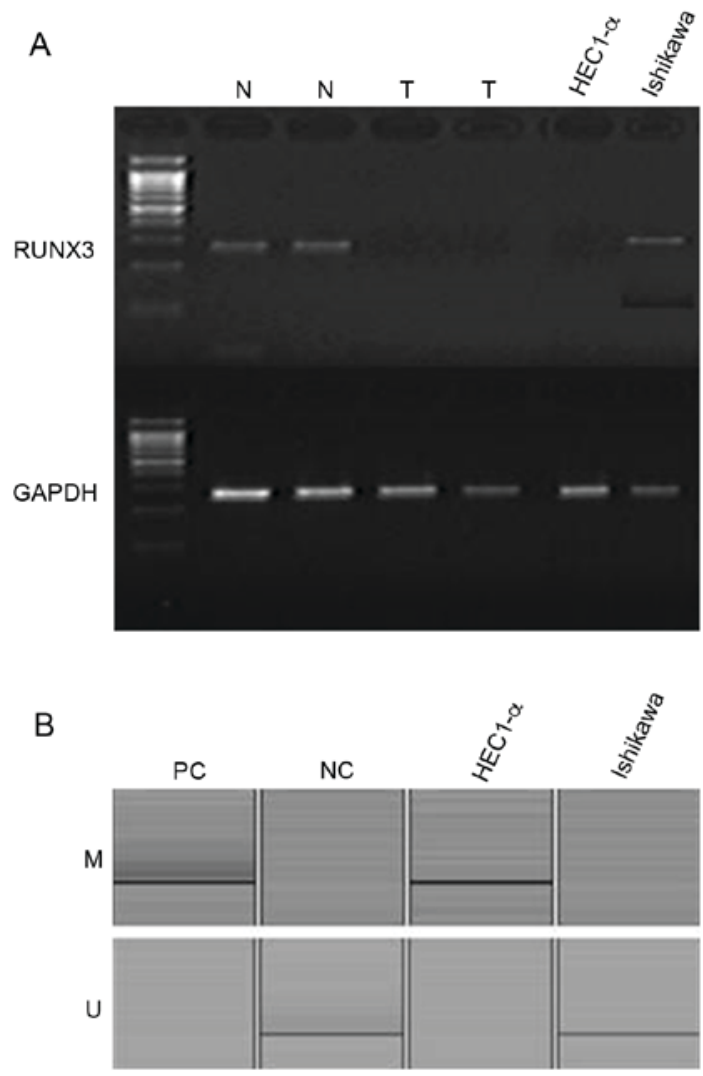

Figure 1. (A) Expression patterns of RUNX3 mRNA in two normal endometrial tissues, two endometrial cancer tissues, and two endometrial cancer cell lines, as determined by reverse-transcription-PCR. GAPDH was used as a standard reference (B) Methylation-specific PCR for the two endometrial cancer cell lines, HEC1- $\alpha$ and Ishikawa. RUNX3, runt-related transcription factor 3; PCR, polymerase chain reaction; $\mathrm{N}$, normal endometrial tissue; $\mathrm{T}$, endometrial cancer tissue; $\mathrm{M}$, methylated; $\mathrm{U}$, unmethylated; $\mathrm{PC}$, positive control; NC, negative control.

tumorigenesis in mammals (3). RUNX3 is located on chromosome $1 \mathrm{p} 36$, which is frequently deleted in various types of tumors and is associated with failure of the TGF- $\beta$ pathway (3), suggesting a mechanism to explain the effects of RUNX3 on the carcinogenesis of malignant tumors. In the present study, the expression of RUNX3 was examined in endometrial carcinoma. The results demonstrated that RUNX3 expression was downregulated due to promoter methylation in approximately half of endometrial tumors. Thus, these data provide important insights into the role of RUNX3 and DNA methylation in endometrial carcinogenesis.

Li et al (5) reported that loss of RUNX3 expression was observed in $61 \%$ of gastric cancer tissues, including $40 \%$ of early cancer tissues and $90 \%$ of the advanced cancer tissues. In addition, consistent with the present study, they demonstrated that loss of RUNX3 expression was caused by hypermethylation of the promoter region or hemizygous deletion of the RUNX3 gene (5). Kim et al (9) reported that hypermethylation occurred in $2.5 \%$ of cervical cancer samples and $12.5 \%$ of endometrial cancer samples. Yoshizaki et al (10) reported loss of RUNX3 protein expression in 12 of 21 endometrial cancer tissues (57\%) by immunohistochemistry and methylation of the RUNX3 promoter region in 18 of 21 endometrial cancer tissues (86\%) and two of nine normal endometrial samples (22\%). This latter study also demonstrated that loss of RUNX3 

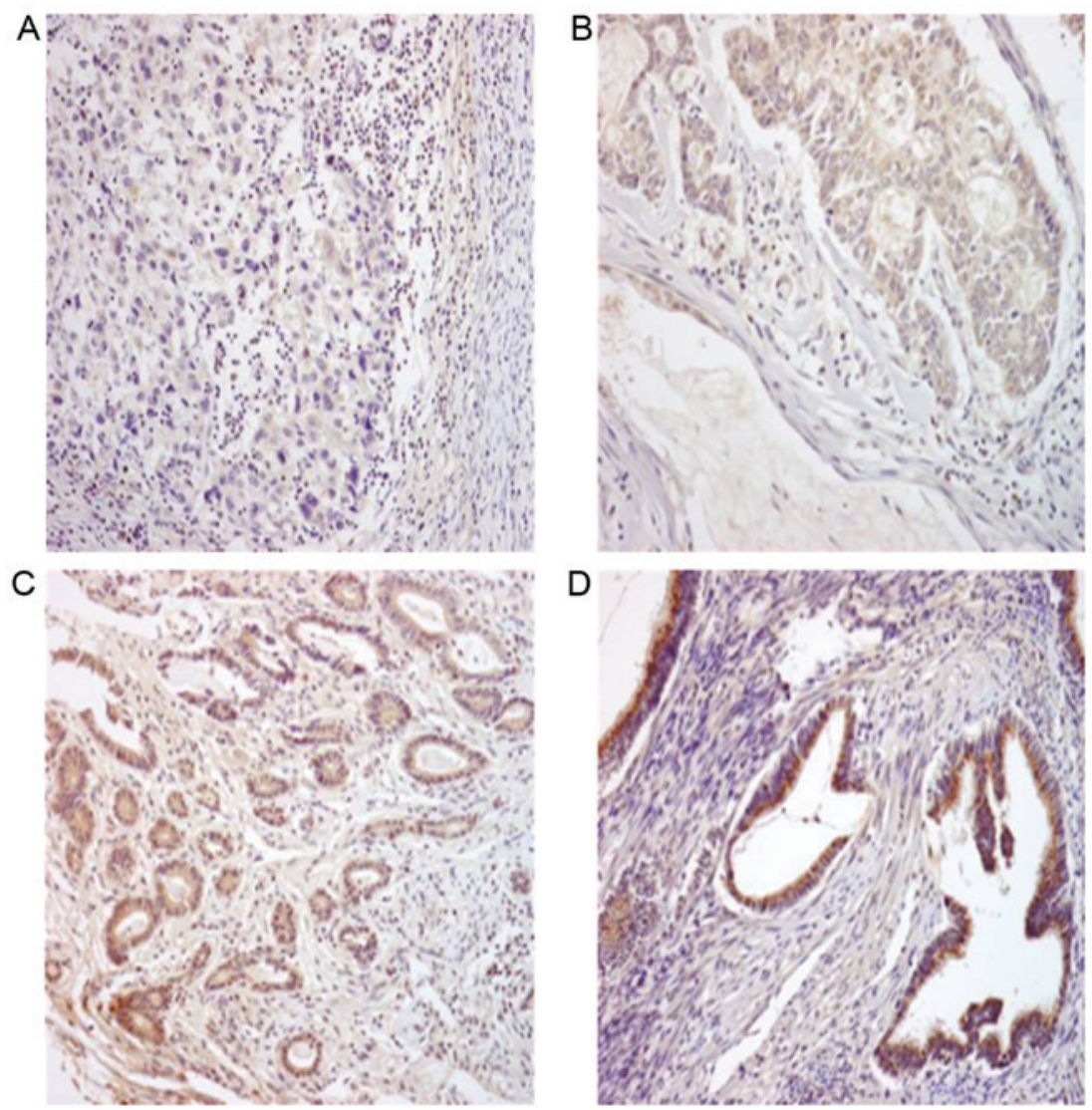

Figure 2. Immunohistochemical staining of endometrial cancer tissues for RUNX3. (A) Grade 3 endometrial cancer sample displays negative staining (0). (B) Grade 2 endometrial cancer sample displays positive +1 staining (C) Grade 1 endometrial cancer displays +2 positive staining. (D) Grade 1 endometrial cancer displays +2 positive staining. Representative images at magnification, $x 200$. RUNX3, runt-related transcription factor 3 .
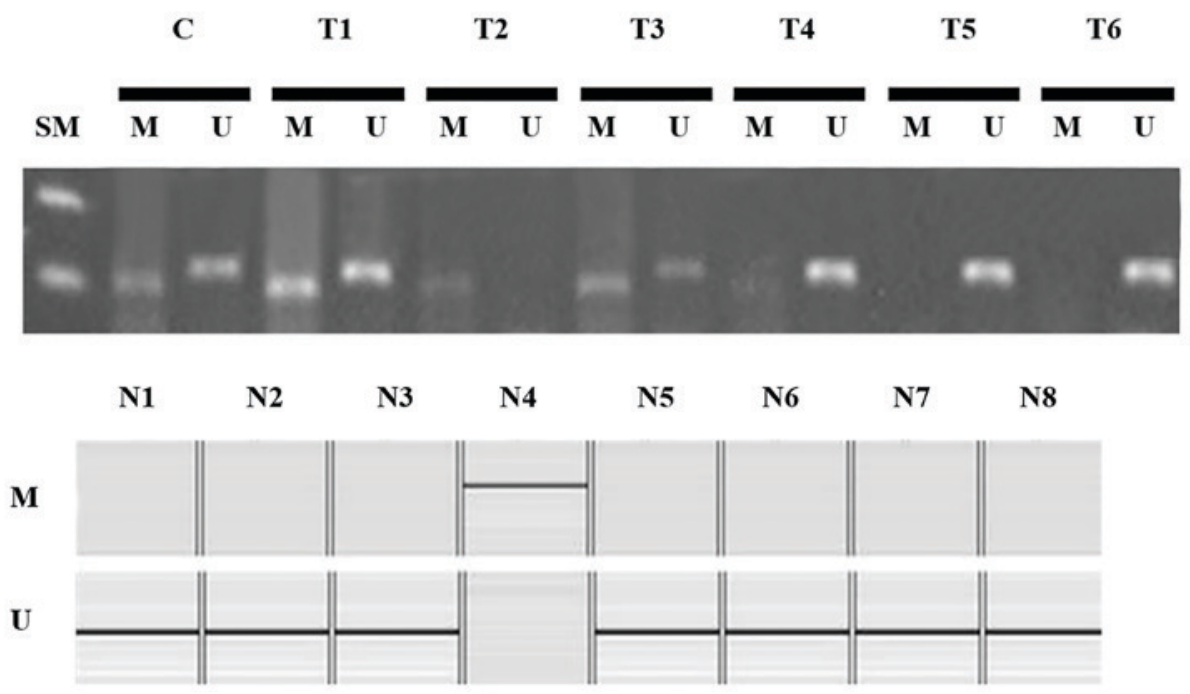

Figure 3. Methylation-specific polymerase chain reaction analysis of the RUNX3 promoter was performed in six endometrial cancer tissues (T1-T6) and eight normal endometrial tissues (N1-N8). Positive findings were observed in T1-T4 and N4 samples. RUNX3, runt-related transcription factor 3; SM, size marker; C, control; M, methylated; U, unmethylated.

protein expression was more frequent in grade 3 tumors than in grade 1 or 2 tumors (10). Similarly, in the present study, immunohistochemistry analysis revealed loss of RUNX3 protein expression in 27 (51\%) of 53 endometrial cancer tissues. Notably, although normal endometrial tissues exhibited strong expression of RUNX3 protein, tumor tissues exhibited primarily weak expression, with only three cases of moderate expression and no cases of strong expression. In samples from patients with stage III cancer, only one of 13 samples exhibited weak RUNX3 expression. Thus, higher histological grade and stage was significantly associated with greater loss of RUNX3 protein expression. 
Table II. Expression and methylation of RUNX3 according to clinicopathological factors.

\begin{tabular}{|c|c|c|c|}
\hline Clinicopathological factors & Number of cases & RUNX3 expression & RUNX3 methylation \\
\hline Age, years $(n=53)$ & & $26(49.1 \%)$ & $33(62.3 \%)$ \\
\hline$<60$ & 28 & 16 & 19 \\
\hline$>60$ & 25 & 10 & 14 \\
\hline \multicolumn{4}{|l|}{ Tumor grade $(n=53)$} \\
\hline G1-2 & 39 & $23^{\mathrm{a}}$ & 25 \\
\hline G3 & 14 & 3 & 8 \\
\hline \multicolumn{4}{|l|}{ FIGO stage $(n=48)$} \\
\hline I & 35 & $24^{\mathrm{a}}$ & 25 \\
\hline III & 13 & 1 & 8 \\
\hline \multicolumn{4}{|l|}{ Myometrial invasion $(n=48)$} \\
\hline$<50 \%$ & 21 & 15 & 16 \\
\hline$>50 \%$ & 27 & 10 & 17 \\
\hline \multicolumn{4}{|l|}{ Lymph node $(\mathrm{n}=48)$} \\
\hline Yes & 4 & 0 & 2 \\
\hline No & 44 & 25 & 31 \\
\hline
\end{tabular}

${ }^{\mathrm{a}} \mathrm{P}<0.05$. RUNX3, runt-related transcription factor 3; FIGO, International Federation of Gynecology and Obstetrics.

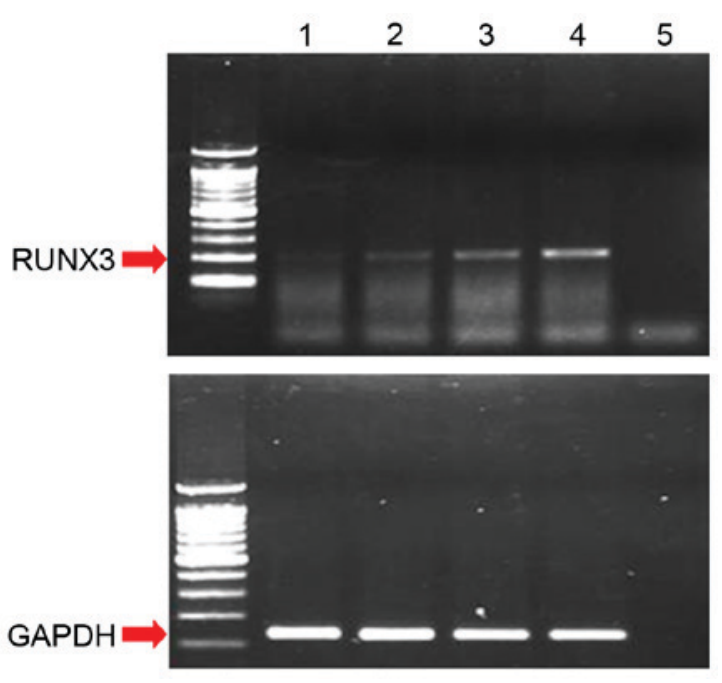

Figure 4. Restoration of RUNX3 mRNA expression in HEC1- $\alpha$ cells following ADC treatment. Lane 1,0 $\mu \mathrm{M}$ ADC control; lane 2, $0.5 \mu \mathrm{M}$ ADC; lane 3, $1 \mu \mathrm{M}$ ADC; lane 4, $5 \mu \mathrm{M} \mathrm{ADC}$; lane 5, no template control. RUNX3, runt-related transcription factor 3; ADC, 5-aza-2'-deoxycytidine.

Additional studies have reported that loss of RUNX3 expression or increased hypermethylation of the RUNX3 promoter is associated with survival in patients with gastric, colorectal and bladder cancers (11-14). Zhang et al (15) examined the methylation of the RUNX3 promoter in epithelial ovarian cancer samples, and no correlation was observed with clinicopathological factors (15). In the present study, methylation of the RUNX3 promoter was also not correlated with prognostic factors, including stage, grade, myometrial invasion and lymph node metastasis. These results are consistent with a report by Park et al (16), who revealed no correlation between methylation of the RUNX3 promoter and clinicopathological prognostic factors in liver cancer (16). These data
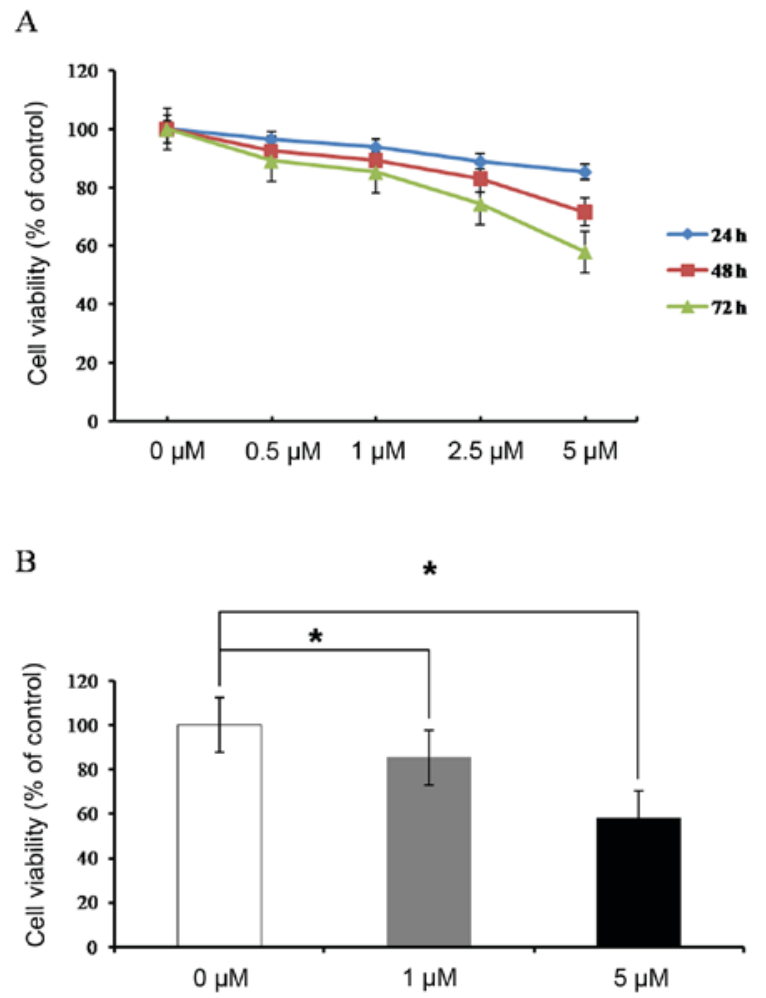

Figure 5. Effect of ADC treatment in HEC1- $\alpha$ cell growth as measured by MTT assay Cell viability is plotted as $\%$ relative to control ( $0 \mu \mathrm{M} \mathrm{ADC})$. ADC, 5-aza-2'-deoxycytidine. (A) HEC1- $\alpha$ cells were treated with increasing dose of ADC for 24, 48, or $72 \mathrm{~h}$. Data are presented as mean + standard deviation, $\mathrm{n}=3$. (B) Quantitation of viable cells treated for $72 \mathrm{~h},{ }^{*} \mathrm{P}<0.05$.

suggest that DNA methylation may occur during the early stages of endometrial carcinogenesis. Notably, the frequency of methylation observed in the present study $(62.3 \%, 33 / 53)$ was lower than that in the study by Yoshizaki et al (10), but 
higher than that observed in liver, ovarian, cervical, and lung cancers $(6,7,9,15)$.

Methylation is a reversible phenomenon; treatment with ADC and trichostatin A has been reported to reactivate RUNX3 mRNA expression in various tumors, including gastric, lung and liver $(5,7,16)$. ADC is a cytosine analog developed as an inhibitor of DNA methyltransferase $3 \mathrm{~B}$ and has been demonstrated to inhibit growth, survival and tumorigenesis in endometrial cancer cell lines (17). In the present study, ADC treatment blocked cell growth and reactivated RUNX3 mRNA expression in HEC1- $\alpha$ cells in a concentration-dependent manner. These results suggest that demethylation and subsequent upregulation of RUNX3 may have resulted in cell growth inhibition in the endometrial cancer cells and ADC may have a therapeutic role in the management of endometrial cancer.

The relevance of RUNX3 silencing in the survival of patients with endometrial cancer could not be investigated in the present study due to the small number of patients with advanced stage cancer and good outcome of patients with early stage cancer. However, the observed association with higher tumor grade and advanced stage implies that RUNX3 promoter methylation and silencing may be important in the development and prognosis of this tumor type. Thus, loss of RUNX3 expression may have applications as a prognostic marker, and RUNX3 may serve as a potential epigenetic target in the treatment of patients with endometrial cancer.

\section{Acknowledgements}

Authors will like to thank Professor Moo Jun Baek, Director of Soonchunhyang Medical Science Research Institute for organizing research equipment.

\section{Funding}

The present study was supported by the Soonchunhyang University Research Fund (grant no. 20180006).

\section{Availability of data and materials}

All data generated during the study are included in this manuscript.

\section{Authors' contributions}

DJ the drafted manuscript and carried out part of the experiments; HK designed and performed immunohistochemical staining; AR participated in the analysis of clinical data; JS analyzed RT-qPCR data; SC carried out methylation specific PCR; GN participated in study design and editing the manuscript; SJ participated in experimental design, data analysis and interpretation, and drafting and reviewing the manuscript. All authors read and approved the final manuscript.

\section{Ethics approval and consent to participate}

The present study was approved by the Institutional Review Board of Soonchunhyang University Cheonan Hospital. Informed consent was provided by all patients.

\section{Consent for publication}

Not applicable.

\section{Competing interests}

The authors declare they have no competing interests.

\section{References}

1. SOG Gynecologic Oncology Committee: Annual report of gynecologic cancer registry program in Korea for 2004 (Jan. 1st, 2004-Dec. 31st, 2004). Korean J Obstet Gynecol 50: 28-78, 2007.

2. Catasus L, Gallardo A and Prat J: Molecular genetics of endometrial carcinoma. Diagno Histopathol 15: 554-563, 2009.

3. Ito $\mathrm{Y}$ and Miyazono $\mathrm{K}$ : RUNX transcription factors as key targets of TGF-beta superfamily signaling. Curr Opin Genet Dev 13: 43-47, 2003.

4. Bae SC and Choi JK: Tumor suppressor activity of RUNX3. Oncogene 23: 4336-4340, 2004.

5. Li QL, Ito K, Sakakura C, Fukamachi H, Inoue KI, Chi XZ, Lee KY Nomura S, Lee CW, Han SB, et al: Causal relationship between the loss of RUNX3 expression and gastric cancer. Cell 109: 113-124, 2002.

6. Xiao WH and Liu WW: Hemizygous deletion and hypermethylation of the RUNX3 gene in hepatocelluar carcinoma. World J Gastroenterol 10: 376-380, 2004.

7. Li QL, Kim HR, Kim WJ, Choi JK, Lee YH, Kim HM, Li LS, Kim H, Chang J, Ito Y, et al: Transcriptional silencing of the RUNX3 gene by $\mathrm{CpG}$ hypermethylation is associated with lung cancer. Biochem Biophys Res Commun 314: 223-228, 2004.

8. Hwang KT, Han W, Bae JY, Hwang SE, Shin HJ, Lee JE, Kim SW, Min HJ and Noh DY: Downregulation of the RUNX3 gene by promoter hypermethylation and hemizygous deletion in breast cancer. J Korean Med Sci 22 (Suppl): S24-S31, 2007.

9. Kim TY, Lee HJ, Hwang KS, Lee M, Kim JW, Bang YJ and Kang GH: Methylation of RUNX3 in various types of human cancers and premalignant stages of gastric carcinoma. Lab Invest 84 : 479-484, 2004.

10. Yoshizaki T, Enomoto T, Fujita M, Ueda Y, Miyatake T, Fujiwara K, Miyake T, Kimura T, Yoshino K and Kimura T: Frequent inactivation of RUNX3 in endometrial carcinoma. Gynecol Oncol 110: 439-444, 2008.

11. Kim EJ, Kim YJ, Jeong P, Ha YS, Bae SC and Kim WJ: Methylation of the RUNX3 promoter as a potential prognostic marker for bladder tumor. J Urol 180: 1141-1145, 2008.

12. Wei D, Gong W, Oh SC, Li Q, Kim WD, Wang L, Le X, Yao J, Wu TT, Huang S and Xie K: Loss of RUNX3 expression significantly affects the clinical outcome of gastric cancer patients and its restoration causes drastic suppression of tumor growth and metastasis. Cancer Res 65: 4809-4816, 2005.

13. Ogino S, Meyerhardt JA, Kawasaki T, Clark JW, Ryan DP, Kulke MH, Enzinger PC, Wolpin BM, Loda M and Fuchs CS: CpG island methylation, response to combination chemotherapy, and patient survival in advanced microsatellite stable colorectal carcinoma. Virchows Arch 450: 529-537, 2007.

14. Soong R, Shah N, Peh BK, Chong PY, Ng SS, Zeps N, Joseph D, Salto-Tellez M, Iacopetta B and Ito Y: The expression of RUNX3 in colorectal cancer is associated with disease stage and patient outcome. Br J Cancer 100: 676-679, 2009.

15. Zhang S, Wei L, Zhang A, Zhang L and Yu H: RUNX3 gene methylation in epithelial ovarian cancer tissues and ovarian cancer cell lines. OMICS 13: 307-311, 2009.

16. Park WS, Cho YG, Kim CJ, Song JH, Lee YS, Kim SY, Nam SW Lee SH, Yoo NJ and Lee JY: Hypermethylation of the RUNX3 gene in hepatocellular carcinoma. Exp Mol Med 37: 276-281, 2005.

17. Cui M, Wen Z, Chen J, Yang Z and Zhang H: 5-Aza-2'-deoxycytidine is a potent inhibitor of DNA methyltransferase $3 \mathrm{~B}$ and induces apoptosis in human endometrial cancer cell lines with the up-regulation of hMLH1. Med Oncol 27: 278-285, 2010. 